\title{
Comprensión de la lectura en alumnos de enseñanza secundaria.
}

\author{
Francisco Sacristán Romero \\ fransacris@ozu.es \\ Universidad Complutense de Madrid
}

\section{Introducción}

La decisión de elegir la realización de este trabajo para conocer más de primera mano la comprensión y asimilación de textos escritos por alumnos de la actual Enseñanza Secundaria en el IES “Alameda de Osuna" del distrito de Barajas en Madrid no es algo gratuito ni que haya surgido por azar.

Estamos interesados especialmente en este asunto por varios motivos: el primero, por algo que nos tocó vivir en nuestros años de Instituto, donde recordamos que algunos profesores en determinadas ocasiones no nos explicaban con suficiente claridad el porqué las ideas principales y secundarias que entresacábamos de los ejercicios de comentarios de texto eran puntuadas hacia arriba o hacia abajo, es decir, qué criterios utilizaban para dilucidar qué argumentos eran los nucleares y cuáles eran los llamados "teloneros".Siempre nos quedó esa curiosidad no satisfecha y con este trabajo creemos que podremos, al menos, conocer algo de lo que fuimos ignorantes en su momento.

Otro de los intereses es el de intentar averiguar alguna de las claves de una plausible separación de algo que a puertas de entrar en la Universidad no tienen claro muchos estudiantes de Secundaria: la distinción entre leer un texto y comprender su filosofía o ideas básicas. Si esta disyuntiva se concibe de forma muy general, la respuesta probablemente tienda a ser pesimista. Este es el caso, según nos comentaron algunos profesores del IES "Alameda de Osuna",de unos cuantos alumnos suyos cuando realizan ejercicios sobre editoriales de prensa diaria. Creen haber entendido la idea básica que expone el editorial cuando ponen con distintas palabras lo mismo que explicita el titular de cabecera del editorial. Y esto, más que un trabajo bien ejecutado, se asemeja a todo un atajo que encuentran los alumnos cuando se enfrentan a un texto complejo como puede ser el editorial, para el que probablemente el equipo de redactores del periódico han estado ocupados una tarde entera para su elaboración.

Por todo ello, debemos partir de la idea de que leer como tal, si somos rigurosos y nos atenemos al planteamiento de entrada con el que iniciamos nuestros argumentos, supone asignar un significado a las palabras y, en esa dirección, comprender lo leído. Sin embargo, hay muchos y variados niveles, tanto cuantitativos como cualitativos, de comprensión y cabe plantearse si, en los de mayor complejidad léxica, sintáctica y semántica, es posible distinguir la capacidad de adquirir nuevos conocimientos mediante la lectura(leer para aprender) de la simple acción de leer(el que lee una novela o un periódico sin mayor interés que el propio reclamo del texto).Si admitimos y estamos mínimamente de acuerdo con esta crucial distinción, más conceptual que real, sería posible enfrentarse a la identificación de las dificultades de ciertos alumnos. Nos da la impresión, más de lo que podemos suponer, con la siguiente expresión del profesor Emilio Sánchez Miguel del Instituto de Ciencias de la Educación de la Universidad de Salamanca que "han aprendido a leer, pero no aprenden leyendo".

\section{Instrumentos}

Elaboramos un material escrito que incluía un apartado de lectura de los tres editoriales de los diarios LA RAZON, EL MUNDO y EL PAIS del 5 de Abril de 1999, seleccionados para la tarea y cuatro 
restantes que se referían a contestar una serie de preguntas abiertas que iban de menor a mayor complejidad según se avanzaba en las contestaciones.

Estas preguntas se elaboraron con la pretensión de analizar las estrategias para la extracción de ideas principales,agilidad y claridad a la hora de poner títulos breves a cada uno de los párrafos de cada editorial,comentarios específicos acerca de lo expuesto por los editorialistas en cada uno de los párrafos y finalmente ver cómo procesaban los alumnos la información cuando se les pedía un resumen final de cada editorial.

Las instrucciones de la tarea que construimos seguían el siguiente orden:

\section{1.-Lectura de los tres editoriales subrayados referentes al tema: Guerra de Kosovo.}

Se pedía a los alumnos que hiciesen una primera lectura de los tres textos, cada uno con su ritmo particular e intentando concentrar al máximo su atención en la tarea. Comentamos a los profesores que explicasen a los alumnos que el objetivo de este primer contacto con los editoriales era hacerse una idea general de cada uno de ellos.

Les dijeron que si alguna palabra les resultaba desconocida en cuanto a su significado debían preguntar para aclarar esas dudas desde un principio, o en su defecto, consultar los términos dudosos en un diccionario.

2.-Extraer de cada párrafo la idea que se considere principal.¿De qué trata el párrafo?

En este paso los profesores explicaban de antemano a los alumnos que lo importante era que hiciesen una segunda lectura del texto con detenimiento en cada uno de los párrafos para ver cuál era, desde la perspectiva de cada uno de los alumnos, el asunto central sobre el que guían las ideas contenidas en cada párrafo. Eramos conscientes de la dificultad de esta tarea para muchos alumnos pero creíamos que era básica para ver la asimilación del material en estas primeras fases.

\section{3.-Poner un título a cada párrafo.}

Para ayudar a las chicas y chicos a comprender mejor la anterior tarea,creímos que podía ser útil el que titularan cada uno de los párrafos.Insistimos a los profesores que en esta fase era muy importante hacerles ver a los alumnos que un "título no es equivalente a un resumen" y que les recordasen que el título tan sólo requiere en muchas ocasiones una palabra o un par de palabras.

Lo realmente esencial era que los alumnos entendiesen que esas palabras empleadas en los titulares debían ser un reflejo del contenido de cada párrafo.

También nos parecía necesario hacer ver a los estudiantes que el título debía hacer referencia al subtema específico del párrafo y no el tema general de todo el texto.

Una vez aclarado el sentido de los pasos 2 y 3 ,los profesores recalcaron a los alumnos que cuando tuviesen un esquema mental definido sobre qué escribir en estas preguntas acerca de la idea de cada párrafo y el título particular que ellos pondrían,redactasen todo en hojas aparte del material entregado para que nos facilitaran a nosotros la labor de análisis de todas sus respuestas.

Por supuesto,contábamos con que algunos alumnos en vez de un título iban a escribir un resumen.Un ejemplo bien elocuente lo encontramos en los títulos que entregó José Luis,alumno de COU y de 18 años:

-Título del editorial de LA RAZON:

-’Fuerzas terrestres,para los albanokosovares,de los aliados". 
-Título del editorial de EL MUNDO:

-"Graves consecuencias tras un error de la OTAN".

-Título del editorial EL PAIS:

-”Organización de la ayuda para evitar la catástrofe".

Por otra parte,pudimos comprobar que algunos de los alumnos se ahorraban el trabajo de escribir lo que se les pedía en la pregunta 2 de las instrucciones de la tarea y empleaban la técnica del "subrayado" para extraer de cada párrafo la idea que consideraban principal.Este método tenía el inconveniente de que contestaban a la pregunta con las mismas palabras que habían usado los editorialistas;de esta forma,nos quedábamos sin la explicación de su elección a través de las propias palabras de cada uno de los alumnos que optaron por el subrayado.

Otro error que percibimos en varias personas consistía en que elegían como título el primer o primeros términos que aparecían en cada uno de los párrafos.Este fallo fue cometido a pesar de que los profesores previamente a la realización de la tarea les matizaron que un buen título es algo cuyo contenido debe estar presente en todas las oraciones del párrafo,y no sólo al principio,en el medio o al final de párrafo.

4.-Desglosar los comentarios de cada párrafo:¿Qué se dice del tema?

5.-Resumen de cada editorial:

5.1.¿¿Podemos quitar algo porque ya lo sabemos muy bien o porque se dice de varias maneras?

5.2.¿¿Hay algo en el texto que se pueda considerar como un ejemplo de algo que ya sabemos?

5.3. ¿Podemos sustituir todo esto por alguna palabra vuestra que “diga lo mismo”?

\section{Procedimiento}

El material de trabajo era anónimo y fue repartido por distintos profesores del IES "Alameda de Osuna" a sus alumnas y alumnos.A pesar de insistir en el anonimato,hubo un significativo número de estudiantes que pusieron su nombre y dos apellidos en las hojas entregadas.

La contestación a las preguntas planteadas se realizó en las clases correspondientes a la asignatura de Lengua durante el mes de Abril de 1999,teniendo la suerte de coincidir con la parte del programa referente a "Lenguaje periodístico" que los profesores explicaron a estos alumnos antes de pasarles los materiales de nuestro trabajo.

Esto les sirvió a ellos mismos para conocer de primera mano el grado de comprensión de alguna de las lecciones de "Lenguaje periodístico" en la modalidad más práctica que planteaban nuestras preguntas.

Siendo plenamente conscientes de los objetivos de nuestro estudio y las características de una gran parte de las variables incluidas,decidimos realizar un análisis de correspondencias múltiples entre las contestaciones a las diversas preguntas.

Nuestro procedimiento buscaba reducir la variabilidad expuesta en los contenidos originales del trabajo a un número menor de dimensiones con el propósito de sondear las semejanzas y diferencias de toda la información posible que plasmaron por escrito los alumnos.

Este modus operandi vimos que podía ser útil para construir una agrupación o clasificación más realista de los sujetos de la muestra en función de sus peculiaridades particulares,ofreciéndonos información adicional sobre las características que guían sus maneras de procesar los datos de los 
editoriales respecto a la comprensión de las ideas principales y secundarias de los textos y expresar resúmenes precisos y sin vaguedades de cada uno de los editoriales.

\section{Resultados}

A continuación exponemos un exhaustivo análisis de los resultados que se extrajeron de cada una de las preguntas y que por las similitudes conceptuales encontradas en las respuestas de los alumnos hemos creído conveniente agruparlos por edades:

$1^{\mathrm{o}} .-14$ años.

$2^{\circ} .-15$ años.

$3^{\circ} .-16$ años.

$4^{\mathrm{o}} .-18$ años.

$5^{\circ} .-19$ años.

$6^{0} .-20$ años.

Para configurar estas agrupaciones hemos empleado tres criterios básicos:

1.-Análisis de la progresión temática de cada uno de los editoriales presentados a través de hacer una parada y reflexionar acerca de las ideas de cada párrafo.

Se pretende con ello percatarse del grado de sensibilidad de los alumnos a los cambios temáticos que introducen cada uno de los párrafos de un mismo editorial y más concretamente dar algún tipo de contestación a preguntas tales como:

¿¿Sigue el párrafo actual hablando de lo mismo que el anterior?

¿¿De qué trata exactamente cada párrafo?

-¿Qué dice el editorial en conjunto de cada uno de los subtemas que plantean los párrafos tomados de forma aislada?

2.-Comprender la idea general de cada editorial.

Este criterio es crucial para nosotros porque equivale en términos formales más academicistas a trabajar con la idea de las macrorreglas presentes en las palabras de cada editorial,o dicho de otra manera,a que los alumnos al realizar la tarea se hagan a sí mismos preguntas como las siguientes:

- ¿Podemos tener una idea más o menos precisa de lo expuesto en cada editorial con la información que se nos presenta?

-¿De qué modo están distribuidos los contenidos propiamente de información y opinión que introduce cada editorial?

-Dentro de cada editorial,¿qué párrafos proporcionan más datos de la realidad del conflicto y cuáles vierten más opiniones particulares?

3.-Reconocimiento de la organización interna del texto.

Se intenta ver cómo los alumnos localizan en los editoriales los contenidos y apoyos vertebradores de la estructura tanto intra-párrafos como inter-párrafos,a través del análisis de sus organizaciones 
particulares referentes a concepciones explícitas e implícitas de la causalidad,la respuesta,la comparación,la descripción somera y profunda y la secuenciación.

Queríamos ver cómo chicas y chicos de cada una de las seis agrupaciones que definimos por edades extraían los antecedentes y consecuentes referentes a la organización de causalidad;problemas y soluciones en el caso de la organización de respuesta;rasgos característicos de cada uno de los párrafos de un editorial concreto respecto a la idea de comparación;elementos importantes que los alumnos tenían en cuenta cuando redactaban la descripción sintética de los editoriales y las fases,pasos o momentos como componentes de la organización secuencial de los párrafos.

A continuación vamos a exponer los análisis individuales y por grupos de edad de nuestra muestra de chicas y chicos de Secundaria.Son los siguientes:

\section{AÑOS:}

-Irene:Esta muchacha cuando no comprende algo intenta explicarlo de forma literal,dando lugar a incoherencias manifiestas,como en el $2^{\circ}$ párrafo del primer editorial y los párrafos $2^{\circ}$ y $5^{\circ}$ del segundo editorial.Nos deja entrever de forma nítida sus juicios y jerarquía de valores en la pregunta 5.2. del primer editorial.Su comprensión del texto parece bastante literal,ignorando la aplicación de una serie de conocimientos previos que la permitirían dar una interpretación de tono más contrastador;un ejemplo ilustrativo de esto es cuando habla de la "poca preparación de la OTAN" en el $1^{\circ}$ párrafo del segundo editorial.No contesta a la pregunta 5 del segundo editorial, hecho que nos resulta paradójico pues es relativamente fácil de contestar.Utiliza como herramienta básica el subrayado.

-Elena:No muestra señales visibles de una estrategia a seguir que sea clara y fácilmente identificable por las personas que analizamos este material.

En muchos casos parece que la comprensión es literal y arbitraria,a modo de mera acumulación de datos sin darse cuenta de la conexión que tienen los párrafos entre sí.No emplea suficientes inclusores para comprender bien el texto.

Ejemplos concernientes a esto último son varias de sus respuestas en las que dice que no se puede suprimir nada porque ya lo sabemos;algunos resúmenes son incorrectos porque se quedan con la primera frase del párrafo aunque en ella no esté contenida la idea central(párrafos $1^{\circ}, 2^{\circ}$ y $3^{\circ}$ del primer editorial y párrafos $2^{\circ}, 3^{\circ}$ y $4^{\circ}$ del segundo editorial).También decir que el primer título que coloca Elena no parece que resulte muy apropiado de acuerdo a la temática del texto.

-Cristina:Sorprenden sus respuestas,dado que demuestra una comprensión inferencial y específicamente sustantiva en algunos de los fragmentos $\left(1^{\circ}\right.$ párrafo del primer editorial y $3^{\circ}$ párrafo del segundo editorial);por contra,en otros fragmentos se acoge a la opción opuesta,como en el $2^{\circ}$ y $4^{\circ}$ párrafos del segundo editorial.No parece que afloren juicios muy significativos,objeto de nuestro interés.Usa el subrayado,pero sólo en algunas ocasiones.

-Verónica:Esta chica demuestra tener una comprensión pobre de los textos presentados.Hace inferencias equivocadas como la del $2^{\circ}$ párrafo del primer editorial y $1^{\circ}$ párrafo del segundo editorial,además de emplear mucha información literal.

Nos resulta particularmente curioso su análisis del $1^{\circ}$ y $3^{\circ}$ párrafos del primer editorial.Los títulos son congruentes con lo que parece que ella ha entendido y esto hace que sobresalgan respecto a los de otras compañeras y compañeros.

-Miriam:En el primer editorial construye explicaciones de los párrafos en función de conocimientos previos,aunque sigue sin entrar en la idea pricipal.En el segundo editorial aporta opiniones cargadas de mucha valoración.Así,el párrafo $8^{\circ}$ lo explica de la siguiente forma:"Clinton no se ha comportado como un buen presidente de los Estados Unidos y no ha estado al nivel de las circunstancias". 
Tanto en el $1^{\circ}$ como en el $2^{\circ}$ párrafo de este segundo editorial confunde la idea principal,quizás dejándose llevar por lo que ya conoce(los nazis).

Emplea información literal para explicar las causas del conflicto.Es en el tercer editorial en el que esta chica expone más diferencias para explicar las causas del conflicto.

Laura:Realiza resúmenes muy extensos y literales en el primer editorial.Nos muestra algunas pinceladas de sus loables ideales humanos en el $3^{\circ}$ párrafo y en la explicación del punto 5.2.

Utiliza subrayados sólo en el tercer editorial.Los títulos que ha escrito no ofrecen gran originalidad.

-Fabiola:Hace valoraciones valientes en el punto 5.3.(“La guerra es una basura”) y en el $3^{\circ}$ párrafo del primer editorial.Nos da la impresión de ser una adolescente minuciosa en su análisis por lo expuesto en los tres editoriales. Manifiesta que Clinton ha actuado sin importarle las muertes de la OTAN.Para Fabiola ha realizado una "chapuza total".

-Edorta:Hace resúmenes generales con buenas aproximaciones temáticas al conflicto.Recoge las ideas de forma muy sintética.Usa el subrayado sólo en los dos primeros editoriales.El título que nos parece más llamativo es el del primer editorial:"El ejército cobarde".

-Resumen del grupo de 14 años:

-Proporcionan una gran cantidad de información arbitraria.

-Sólo unas pocas personas utilizan conocimientos previos.

-Sus opiniones no son valorativas, excepto Fabiola.

-Los títulos suelen ser coherentes con los resúmenes y son a la vez "resúmenes de los resúmenes".Extraen continuamente información literal y emplean profusamente el subrayado.

En general,no aportan recursos suficientes.Recurren a información literal dando lugar a inferencias incorrectas.No emplean suficientes inclusores y no se dan cuenta de los nexos de unión de los párrafos.

\section{AÑOS:}

-Ana:Sus resúmenes incluyen la idea principal y están bien conseguidos,pero siguen siendo literales.No realiza muchas valoraciones.Se salta párrafos y emplea la técnica del subrayado.

-Beatriz:Se da cuenta de los nexos causales entre párrafos.Es literal en sus expresiones y apenas usa el subrayado.De sus contestaciones no hemos podido extraer mucha información dado que es parca en palabras.

-María:En el $3^{\circ}$ párrafo del segundo editorial pensamos que hace una inferencia incorrecta cuando explica de que "Si no hubiera habido periodistas no se hubiera ido tan lejos".No integra y entrelaza con agilidad y soltura la información. Tampoco encuentra la idea principal en algunas ocasiones como en el párrafo $1^{\circ}$ del tercer editorial.Desglosa mucho los editoriales.No admite el recurso de las ideas redundantes,exigiendo que se dé más y distinta información.

-Micaela:En el primer editorial capta bien la idea y es consciente de lo que se repiten distintos argumentos pero sigue siendo literal en sus expresiones.En general parece muy segura de lo que dice.Utiliza la técnica del subrayado.

-Laura:Hace inferencias incorrectas en los párrafos $1^{\circ}$ y $2^{\circ}$ del primer editorial y correctas en los párrafos $6^{\circ}$ y $7^{\circ}$ del segundo editorial.En este segundo editorial echa mano de los conocimientos 
previos.Es valorativa en el título que da a los párrafos en el punto 5.2.Reconoce no poder englobar en una palabra todo un texto.Parece realizar un proceso de inferencias complejo pero incorrecto.No es literal.Emplea el subrayado en el tercer editorial.

-Patricia:Es literal.Responde bien a la pregunta 5 en el primer editorial.Las ideas están conseguidas aunque con dificultad.

-Alexia:Es relativamente partidista y eso la lleva en ocasiones a no entender lo que dicen o quieren decir realmente los editoriales.No realiza un resumen del conjunto del editorial,sólo de los párrafos que la llaman más la atención.Es imaginativa a la hora de titular.

-Luna:Esta chica es una de las personas que más se aproximan a nuestros objetivos de partida de toda la muestra analizada.Realiza las tareas con profundidad de miras y no se deja llevar por extrapolaciones sin sentido,hecho que se constata en el resto de los adolescentes.Sin embargo,no consigue buenos títulos y además los hace muy extensos en nuestra opinión.Sí vemos que parece manejar datos que no se ven en sus compañeras y compañeros.

\section{Resumen del grupo de 15 años:}

En general entienden mejor cómo ocurren los hechos;nos damos cuenta de esto en las interpretaciones del $1^{\circ}$ y $2^{\circ}$ párrafos del primer editorial y el $2^{\circ}$ y $3^{\circ}$ párrafos del segundo editorial,que no eran entendidos por los de 14 años.No obstante,siguen estando muy pegados al contexto de las informaciones y en muchos casos no se percatan de las relaciones entre los distintos párrafos,extendiéndose demasiado en las explicaciones y sin un uso aparente de estrategias.Algunos alumnos de este grupo han resultado ser tremendamente valorativos en sus apreciaciones.Sigue habiendo personas que no entienden los editoriales en su conjunto.Estos alumnos se podrían dividir en dos subgrupos:

$1^{\circ}$.-Personas menos literales y más valorativas,que suelen realizar inferencias equivocadas.

$2^{\circ}$.-Personas literales que escriben "mucha paja”.

\section{AÑOS:}

-Enrique:Es la única persona de esta edad que se incluye en nuestra muestra.Emplea el subrayado y no piensa que sea redundante.Nos parece que sus tres títulos son adecuados.Los resúmenes que realiza son bastante literales, hecho que hace que no podamos entresacar excesiva información de este chico.

\section{AÑOS:}

-Arancha:La comprensión del material es el de una "experta" para su edad.Todas las ideas principales han sido captadas y expuestas con claridad.Los títulos son buenos.La pregunta 5 está contestada de una maera que "cualitativamente" supera con creces al resto de compañeros.No es literal y se da cuenta de la continuidad de las ideas.Tampoco es excesivamente valorativa en sus comentarios.

-José Luis:Su comprensión es inferencial,no literal.Se da cuenta de aquello que repite pero su fallo estriba en que no realiza el análisis por párrafos sino de forma global.En todo caso,están bien logradas sus apreciaciones.

-Gonzalo:Los títulos que escribe enfatizan las ideas principales y los resúmenes son la explicación de lo expresado en los títulos.Hay hilo de conexión y de continuidad en sus argumentos.Las ideas están bien conseguidas y no nos parece que haga inferencias erróneas.

Resumen del grupo de 18 años:

Sólo en determinadas ocasiones,las inferencias que hacen son más sustantivas y no arbitrarias que los 
grupos de menor edad.Han comprendido los textos con más profundidad y menos literalidad que el resto de compañeros.Recogen la idea principal en los títulos y desde ellos desarrollan los resúmenes.Leen detenidamente y explican los textos con sus palabras;tan sólo algunos usan los subrayados.

Se percatan de continuidades entre los párrafos y se ciñen rigurosamente a la información dada.Recurren a conocimientos previos para entender lo que dicen pero no emiten juicios sin sentido,o al menos eso parece.

\section{AÑOS:}

-María del Mar:Esta chica juega con juicios de valor de forma más lígera que sus compañeros,dejándolo ver en los títulos;éstos se estructuran como buenos resúmenes.M ${ }^{a}$ del Mar se sirve de inferencias basadas en valores bien forjados.Las ideas están bien explicitadas.No hay nada literal;sus comentarios brotan de sus propias palabras.

-Almudena:Comprende bien los editoriales y sus títulos se basan en las ideas principales.

-Carlos:Realiza muchas inferencias desde sus propias palabras.Capta bien las ideas y divide con sentido común el texto.No analiza los editoriales párrafo por párrafo,siendo valorativo en sus comentarios.

-José:Las inferencias de este chico son descomunales.Un ejemplo es cuando dice:”No sabía que la OTAN era tan torpe".Utiliza frases literales y llamativas del texto para colocar los títulos.No realiza un análisis intrapárrafos.

-Antonio Luis:No es nada literal.Es un tanto "naif" en sus comentarios.Compara mucho los tres editoriales,analizando los puntos de vista de cada editorial.Emplea palabras muy elocuentes: "interés",'Inconsciencia","tragedia".

-Susana:Es incisiva en el primer editorial,dando a entender que los que más sufren son los más inocentes.Realiza inferencias significativas y no se atiene a comentarios literales.

Resumen del grupo de 19 años:

Sus análisis son muy similares al grupo de 18 años.Hacen caso omiso de la literalidad de los textos,dando pie a inferencias jugosas que no vemos en los otros grupos de edad.

Son más valorativos y recurren más a sus conocimientos previos que el resto de sus compañeros.

20 AÑS:

-Pablo:Aparecen incongruencias junto al subrayado de palabras clave.Repite ideas en su resumen aunque en el punto $\mathrm{B}$ diga que no se repite nada.La idea que manifiesta del tercer editorial está equivocada.Piensa que es un error de cálculo no incluir que Milosevic fuera a reaccionar como lo ha hecho.Esta explicación es posible que esté influida por lo dicho en los otros dos editoriales.

-Juan Jesús:Manifiesta argumentos más literales que su compañero Pablo y otras personas de 19 años.Utiliza bastante la coletilla "Yo creo que" cuando empieza cada punto explicativo de la tarea.

Resumen del grupo de 20 años:

Tanto en sus inferencias como en su análisis de las ideas principales,sus conclusiones se alejan bastante al grupo de 19 años.Incluso,nos atreveríamos a decir,que hay personas de 19 y 18 años que interpretan más profundamente alguno de los editoriales. 
Aunque se constatan evidencias notables entre Pablo y Juan Jesús de 20 años,sí que podemos ver un cierto acopio de ideas irrelevantes que vemos menos presente en los grupos de 18 y 19 años.Nos parecen,en definitiva,que se atienen con más rigor a la literalidad del texto.Están "más pegados" al aquí y ahora del texto.

\section{Conclusiones}

Tras el análisis de los resultados podemos sostener que efectivamente las hipótesis desde las que partíamos se han confirmado en su mayoría.

Así los lectores de menor edad y por ello,en principio,más novatos,realizan una lectura cuyos procesos son más simples,inmaduros y en algunos casos incompletos mientras que los lectores de mayor edad y por ende,teóricamente más expertos,realizan una lectura que implica procesos cognitivos más complejos,adecuados y profundos.

De acuerdo a nuestros objetivos de partida,lo anteriormente expuesto se podría concretar en los siguientes puntos:

-los lectores jóvenes suelen realizar resúmenes literales utilizando en muchos casos la técnica del subrayado.Los de más edad,por el contrario,hacen resúmenes en los que traducen el contenido del editorial a sus propias palabras,dándole una mayor amplitud de miras a la información manejada.

-Del punto anterior se desprende el hecho de que los primeros expresan ideas incorrectas fruto de los atajos que toman.Esto,sin embargo,no es frecuente verlo en el segundo grupo que al haber "flitrado" la información tiende a expresar ideas correctas.

-Los más novatos parecen,en muchas ocasiones,que no son capaces de reconocer la conexión existente entre los diferentes párrafos sin poder,de esta forma,establecer relaciones causa-efecto,hecho que si se entrevé en los más expertos.

-Por último,encontramos que los novatos no intentan integrar el conocimiento que tienen de otras áreas mientras que los expertos si lo hacen.Esto constituye otra razón por la que los novatos no llegan a comprender la lectura.

No obstante,consideramos necesario puntualizar que estos resultados no se dan en todos los casos;como siempre,podemos encontrar diferencias individuales que podrían ejemplificarse en las personas de Pablo y Juan Jesús,de 20 años.Estos chicos se acercan más que a un nivel avanzado,a uno mediocre de comprensión.Para realizar esta afirmación nos hemos basado en que aparentemente no logran entresacar las ideas centrales de los textos,realizando inferencias incorrectas y estando bastante apegados a la literalidad de los contenidos.

Pero también podemos encontrar diferencias individuales en los grupos de "novatos",como puede ser el caso de Luna de 15 años cuyas ideas centrales están bien conseguidas,basando sus decisiones en procesos más maduros.

Respecto a las inferencias realizadas,también podemos encontrar importantes diferencias particulares entre las alumnas y alumnos.Nos sorprende encontrar que sean los más jóvenes de la muestra los que presentan posiciones más valorativas en contraposición con los mayores de la muestra que nos parecen han sido más objetivos y cautelosos en sus opiniones,sin hacer juicios de valor por doquier.

No obstante,si analizamos con más profundidad los juicios que realizan,esta primera sorpresa se torna en algo que según lo expuesto en el cuerpo teórico se podía predecir.Nos referimos a que los juicios que realizan se desprenden de sus ideas implícitas y de la información literal del texto.Queremos decir,en definitiva,que no han integrado y construido su propia versión de la realidad en función de lo expuesto en los editoriales y sus ideas implícitas.Dicho de otra forma:se han dejado llevar por uno de 
los dos factores,sin ejercitar una visión crítica e integrar diversos conocimientos como parece recomendable en este caso.Algunos ejemplos ilustrativos son cuando una de las chicas de la muestra manifiesta que "La guerra es una basura" o cuando otra habla sobre Clinton,etc...

Otro aspecto que queremos reseñar es el hecho de que los sujetos de 11 y 12 años tuvieron que ser descartados.Esto también lo podemos interpretar como un dato a favor de nuestras hipótesis,es decir,comprobamos que los más jovencitos e inexpertos de la muestra inicial no tienen a su disposición o no logran poner en marcha los mecanismos requeridos para este tipo de lectura.

Para terminar hemos intentado reflexionar sobre el hecho de que son pocos los sujetos que han intentado resumir el tercer editorial y muchos de los que lo hacían era a través de la técnica del subrayado a pesar de que no hubieran utilizado ésta con los otros dos editoriales.Pensamos que una posible causa pudo ser el no dar con la selección del editorial adecuado conforme a los cuatro criterios que utilizamos. Ningún editorial cumplía totalmente las exigencias que requerían los cuatro criterios mencionados; por eso decidimos centrar nuestra elección en las descripciones-diagnóstico de la situación y en las interrelaciones entre los distintos argumentos empleados.En base a esto podemos postular que sobreestimamos la lógica interna que seguía este último editorial de EL PAIS.

Esperamos que estos resultados puedan ser útiles para la marcha presente y futura de las investigaciones que sigan ésta o parecida línea dentro del marco de la asignatura.En definitiva,nuestro deseo es que este trabajo aporte su granito de arena respecto a tener indicadores sólidos cuando nos acerquemos como lectores u obervadores a la comprensión de textos escritos,y en especial los de prensa diaria.

\section{Bibliografía}

BERNÁRDEZ, E.(1982). Introducción a la lingüística del texto. Madrid: Espasa Calpe.

COLL, C.(1989). Conocimiento psicológico y práctica educativa. Barcelona: Barcanova.

EDWARDS, D. y MERCER,N.(1987). El desarrollo de la comprensión en el aula. Barcelona: Paidos/MEC.

GARCÍA MADRUGA, J.C. y MARTÍN CORDERO, J.I.(1987). Aprendizaje. Comprensión y Retención de Textos. Madrid: Estudios de Educación a Distancia.

GELB, I.J.(1976). Historia de la escritura. Madrid: Alianza.

LÓPEZ RODRÍGUEZ, N.(1982).Cómo valorar textos escolares. Madrid: Cincel.

LURIA, A.R.(1980). Conciencia y Lenguaje. Madrid: Pablo del Río Editor.

MAYOR, J.(1984).Texto y discurso,En J.Mayor (Ed.) Psicología del pensamiento y del lenguaje. Vol. I. Madrid:UNED.

PUENTE, A.(1991). Comprensión de la lectura y acción docente. Madrid: Pirámide.

SÁNCHEZ MIGUEL, E.(1990).La comprensión de textos en el aula. Salamanca: ICE de la Universidad de Salamanca. 